higher morbidity than, they would have had if they had been treated by simple suture.

It remains to examine the late results of this series to see to what extent the definitive operation did reduce the risk of further major symptoms, which would be predicted within two years in $59.6 \%$ of these patients if treated by simple suture. In fact, after vagotomy only $10.3 \%$ of cases had poor results, while a further $5 \%$ were untraceable. Included among the poor results are two patients with incomplete vagotomies, one of whom has now undergone transthoracic completion, while the other has become symptom-free. In round figures, it seems that the number of poor results has been cut from $60 \%$ to $10 \%$ in this group, so $50 \%$ have been saved from further serious ulcer disability within the relatively short period of this follow-up.

\section{Conclusion}

We consider that the present treatment of choice for patients with perforated duodenal ulcers, known by their history or shown by the operative findings to be chronic, is emergency vagotomy and pyloroplasty. Patients lacking such evidence of chronicity or concomitant bleeding should be treated by simple suture of the perforation, as should those judged unfit for the more major procedure on account of their very poor general condition.

\section{Summary}

A series of 61 patients with perforated duodenal ulcers treated by vagotomy and a drainage procedure is presented.

The prognosis following simple suture of perforated duodenal ulcer is discussed, and indications to be employed in selection for primary definitive procedures are assessed. Historical or operative evidence of chronicity carries a $60 \%$ risk of further ulcer symptoms, whereas acute ulcers usually follow a benign course after perforation.

The choice of definitive procedure to be employed as an emergency rests between partial gastrectomy and a vagotomy- and-drainage procedure. Reasons are given for preferring the latter.

In this series vagotomy and a drainage procedure were carried out with no higher mortality or morbidity than would be expected for simple suture. The late results were satisfactory in that only $10 \%$ experienced serious symptoms, as compared with $60 \%$ of such patients after simple suture.

Vagotomy and a drainage procedure is recommended as the treatment for those perforated duodenal ulcers with historical or operative evidence of chronicity.

We should like to thank the surgeons of the Leicester Royal Infirmary for permission to study their patients, and in particular Mr. D. C. McGavin for much helpful criticism.

\section{REFERENCBS}

Avery Jones, F., and Doll, R. (1953). Brit. med. F., 1, 122.

Beattie, A. D. (1950). Lancet, 1,525.

Burge, H., and Clark, P. A. (1959). Brit. med. F., 1, 1142.

Desmond, A. M., and Seargeant, P. W. (1957). Brit. F. Surg., 45, 283.

Dragstedt, L. R. (1959). Proc. roy. Soc. Med., 52, 835.

Gilmour, J. (1953). Lancet, 1, 870.

Graham, R. R. (1937). Surg. Gynec. Obstet., 64, 235.

Harbrecht, P. J., and Hamilton, J. E. (1960). Ann. Surg., 152, 1044

Herrington, J. L. (1961). Surgery, 49, 827.

Heslop, T. S., Bullough, A. S., and Brun, C. (1952). Brit. F. Surg., 40, 52 .

Illingworth, C. F. W., Scott, L. D. W., and Jamieson, R. A. (1946). Brit. med. F., 1, 787.

Jones, P. F. (1960). Postgrad. med. 7., 36, 768.

Judin, S. S. (1937). Surg. Gynec. Obstet., 64, 63.

Lewis, B., and Hamilton, J. E. (1956). Amer. Surg., 22, 204.

Lowdon, A. G. R. (1952). Lancet, 1, 1270.

Muir, A. (1949). Brit. F. Surg., 37, 165

Nuboer, J. F. (1951). Lancet, 2, 952.

Pierandozzi, J. S., Hinshaw, D. B., and Rogers, F. (1957). West. F. Surg., 65, 139.

_- and Stafford, C. E. (1960). Amer. 7. Surg., 100, 245.

Stammers, F. A. R. (1955). Ann. roy. Coll. Surg. Engl., 17, 373.

Taylor, H. (1957). Gastroenterology, 33, 353.

Welbourn, R. B., and Johnston, D. A. (1961). In British Surgical Practice, Surgical Progress, edited by E. R. Carlin and J. P. Ross, p. 301. Butterworths, London.

Wells, C. (1955). Ann. roy. Coll. Surg. Engl., 16, 145.

\title{
Results of Vagotomy with the Electrical Stimulation Test : An Interim Report
}

\author{
HAROLD W. BURGE,* M.B.E., M.B., F.R.C.s. ; ALAN MORTON GILL, $\dagger$ M.D., F.R.C.P. \\ RONALD H. LEWIS, $\ddagger$ M.B., B.CH., B.SC., F.R.C.S.
}

Brit. med. F., 1964, 2, 17-21

A report of the results of vagotomy with simple drainage for duodenal ulcer can be read only in the light of an understanding of the causes of recurrent ulceration.

If we exclude the Zollinger-Ellison syndrome, then there are two causes usually recognized.

1. Incomplete Nerve Section.-This is well established as the most important cause of recurrent ulceration. Dragstedt (1948) has shown in the laboratory that small retained nerve trunks may give rise to considerable acid secretion, and it has been demonstrated, by using the electrical stimulation test (Burge, unpublished work), ${ }^{1}$ that small retained trunks may cause recurrent ulceration in man. The incomplete-nerve-section

* Surgeon, West London Hospital, London.

+ Physician, West London Hospital, London.

t Pesident Assistant Surgeon, West London Hospital, London.

${ }^{1}$ For a description of the vagotomy test instrument, Mark 2, see page 39. rate when the electrical stimulation test is not used is generally considered to be about $30 \%$.

2. Antral Retention.-The evidence that antral retention is a cause of recurrent ulceration is strong, and this cause is widely accepted in the world of gastric surgery. Such ulcers are generally thought to be due to an augmented hormonal phase of acid secretion from an antrum deranged by retention and by $p \mathrm{H}$ change.

As the results given in the present paper depend in part on this important cause of recurrent ulceration, some of the evidence in support of it is summarized below.

1. Antral retention causes secretion of acid in a denervated (Heidenhain) pouch in dogs. So do $\mathrm{pH}$ changes.

2. When vagotomy was done without either pyloroplasty or gastrojejunostomy, gastric retention was common, and lesser-curve 
gastric ulcer was sometimes a complication when retention was present. None seemed to doubt that these gastric ulcers were caused by retention.

3. Lesser-curve gastric ulcer has been recognized for many years in duodenal ulceration with stenosis and retention. Carman's (1917) paper was perhaps the first to record this.

4. When Polya gastrectomy with "duodenal " closure is done the gastrojejunal ulcer rate is only 2 to $3 \%$. If antral exclusion with mucosal retention is used the gastrojejunal ulcer rate is exceedingly high. The difference can lie only in the antrum and presumably the gastrin output from its retained mucous membrane. These ulcers are apparently cured if the antrum is excised. Even when the Bancroft operation of prepyloric closure with mucosal ablation is done, if as little as $\frac{1}{2}$ in. $(1.3 \mathrm{~cm}$.) of gastric mucosa is left in position (and this apparently is how Bancroft (1932) performed the operation), the gastrojejunal ulcer rate is high when compared with the standard gastrectomy (Burge, 1958). The recurrent ulcer is caused, so we believe, by food entering a prepyloric mucosal remnant made alkaline by the duodenal contents (Fig. 1).

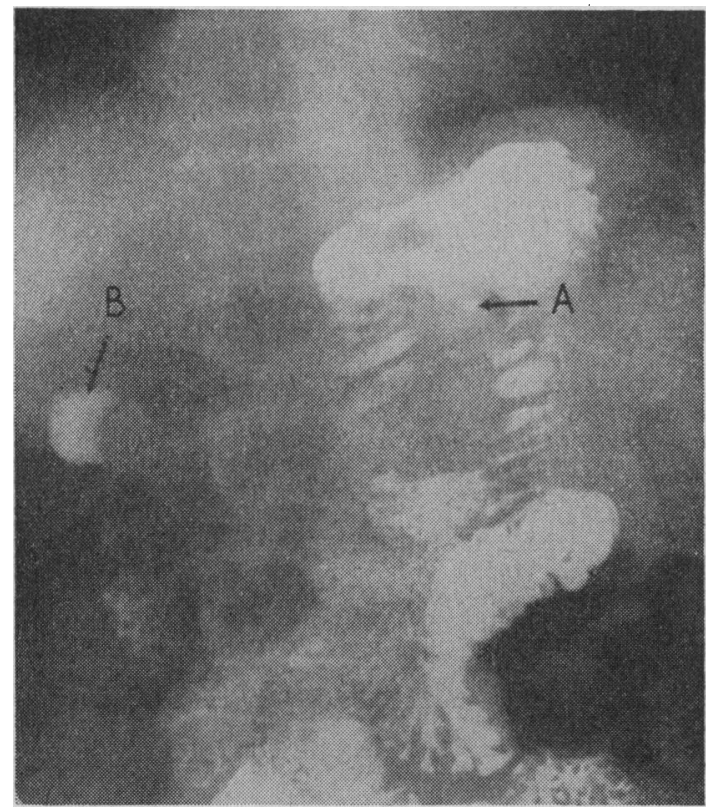

FIG. 1.-A=Anastomotic ulcer. $\mathrm{B}=$ Prepyloric mucosal remnant.

Gastrin cannot as yet be estimated in the circulating blood. Proof, therefore, is lacking that gastric retention causes these ulcers by augmenting the hormonal phase of gastric-acid secretion. Nevertheless, we must accept the retention theory in the aetiology of these lesions even though we may refuse at present to believe that they are caused by excessive gastrin release. It is well for us to remember that gastric, duodenal, and gastrojejunal ulcers are caused, in patients with Zollinger-Ellison syndrome, by a substance identical-or almost identical-with gastrin.

\section{Results of Total Abdominal Vagotomy and Simple Drainage Without Electrical Stimulation Test}

When vagotomy and simple drainage is done withour the stimulation test, the recurrence rate lies generally between 5 and $15 \%$. Rigler (1959), reporting the results in the University of Chicago, found the recurrence rate after vagotomy and gastrojejunostomy to be $10.6 \%$. Weinberg et al. (1956) reported a $5 \%$ recurrence rate after vagotomy and pyloroplasty, and stated:

"Failure to heal the ulcer by vagotomy is almost invariably due to incomplete interruption of the nerves." Stempien et al. (1959) also found a 5\% recurrence rate after vagotomy and pyloroplasty, and in their cases an incomplete-nerve-section rate of $30 \%$ as shown by the insulin test. In London, Austen and Edwards (1961) had a 5\% recurrence rate after vagotomy and simple drainage. In each recurrent case vagotomy was shown to be incomplete by the insulin test. Edwards et al. (1960) and Hoerr (1959), in America, each reported $13 \%$ recurrence after vagotomy and gastrojejunostomy.

Burge and Clark (1960), reporting the 10-year results of a nation-wide series of patients from several cities in England, found a recurrent ulcer rate of $4.8 \%$ after vagotomy and pyloroplasty and $4.6 \%$ after vagotomy and gastrojejunostomy.

A few surgeons greatly experienced in the operation have given very low figures (Feggetter, 1959, 1.5\%; Holt, 1959, $0.8 \%$ ). Clearly, when the operation is done without the electrical stimulation test the recurrent ulcer rate depends very much on the skill and experience of the surgeon. When the test is used this factor is eliminated.

\section{Results when Electrical Stimulation Test is used}

The purpose of this paper is to record the results in 200 patients (165 men and 35 women) with vagotomy and simple drainage for duodenal ulcer in whom the electrical stimulation test (Burge and Vane, 1958) was used.

Selective nerve section is designed to prevent post-vagotomy diarrhoea. In itself it is not related to recurrent ulceration, although the selective technique no doubt increases the chances of complete nerve section. Nevertheless it should perhaps be stated that of these 200 patients total abdominal vagotomy was performed in $26(13 \%)$, posterior selective vagotomy in 13 $(6.5 \%)$, bilateral selective vagotomy in $53(26.5 \%)$, and anterior selective vagotomy in 108 (54\%).

Pyloroplasty was used in 114 and gastrojejunostomy in 86 .

Seven patients are known to have died since operation. In each case the cause of death is known; none was due to peptic ulceration.

Four patients have been lost to follow-up. Three of these were from overseas and were lost after their return home. A fourth left London, having been followed for two and a half years, and cannot now be traced. Of the 200 patients, 185 were followed for more than one year, 136 for more than two years, 87 for more than three years, 59 for more than four years, 35 for more than five years, 15 for more than six years. There were two cases of recurrent ulceration.

Case 1.-A man aged 41 (blood group $\mathrm{O}$, non-secretor). A large gastrojejunal ulcer was found on $x$-ray examination six months after operation in 1960 (vagotomy and gastrojejunostomy). The electrical stimulation test had been used at the first operation. At the second it was applied and showed the presence of two small intact nerve trunks, giving pressure rises of 2 and $3 \mathrm{~cm} . \mathrm{H}_{2} \mathrm{O}$. After section of these retained nerves completeness of nerve section was shown by the test. The gastrojejunostomy was unpicked and a pyloroplasty made. Either vagal section had been complete at the first operation and regeneration had taken place or, as we have reason to think, a fault in the test at that early time had been responsible for incomplete nerve section. He remains symptom-free two years later. Apparent cause of recurrence : a persistent cephalic phase of gastric acid secretion from incomplete nerve section.

Case 2.-A man aged 48 (blood group $\mathrm{O}$, non-secretor). Vagotomy and gastrojejunostomy had been performed in this patient with severe duodenal stenosis five years previously. Nerve section was proved complete by the test. Eighteen months later a large gastrojejunal ulcer was found on the gastric side of the stoma (Fig. 2). There was severe antral retention between the stenosed duodenum and the short-circuit stoma (Fig. 3). This ulcer healed spontaneously. Three years later he was perfectly well. Apparent cause of recurrence : an augmented hormonal phase of gastric acid secretion from antral retention.

Case 3, although showing a transient lesser-curve ulcer, cannot be regarded as a vagotomy failure, because of the very transient nature of the lesion. It is important in that it throws an interesting light on the aetiology of lesser-curve gastric ulcer, for it lends support to the view that this condition is due to nothing more than antral retention. 
Case 3.-A man aged 37 (blood group A). Vagotomy and pyloroplasty was performed for chronic duodenal ulceration. No duodenal narrowing was present. Completeness of vagal section was proved by the electrical stimulation test, and a Heineke-Mikulicz single-layer pyloroplasty was made. Within two months of operation his symptoms recurred, and $x$-ray examination showed a gastric ulcer on the lesser curve (Fig. 4). This finding at once called to mind gastric ulcers secondary to gastric stasis when vagotomy was performed without any form of drainage operation. In this case it was known that there could be no organic narrowing, either at the pyloroplasty or in the duodenum, and this was confirmed by barium-meal examination (Fig. 5). In spite of this there was antral retention (Fig. 6). The insulin test indicated complete nerve section. Four months later a barium-meal examination showed that the stomach emptied normally and no ulcer crater was present. The patient has remained symptom-free for two and a half years. Apparent cause of recurrence: a hormonal phase of gastric acid secretion temporarily augmented by loss of gastric motor function following vagotomy.

Two other cases in this series are of interest, although in neither was there evidence of recurrent ulceration. In both cases bleeding occurred, apparently from antral retention due to faulty drainage operations.

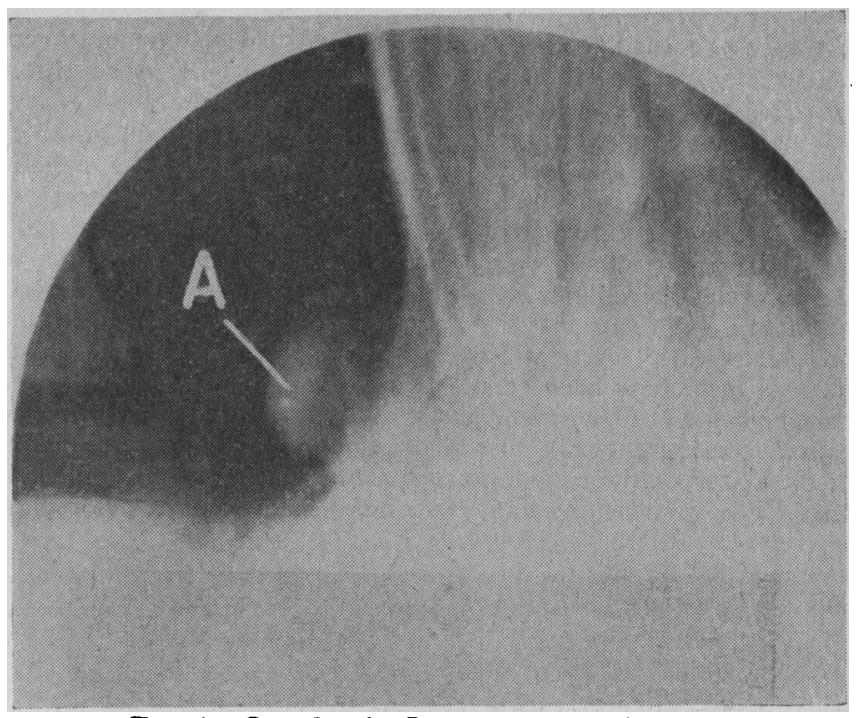

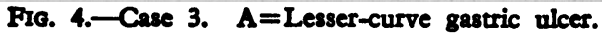

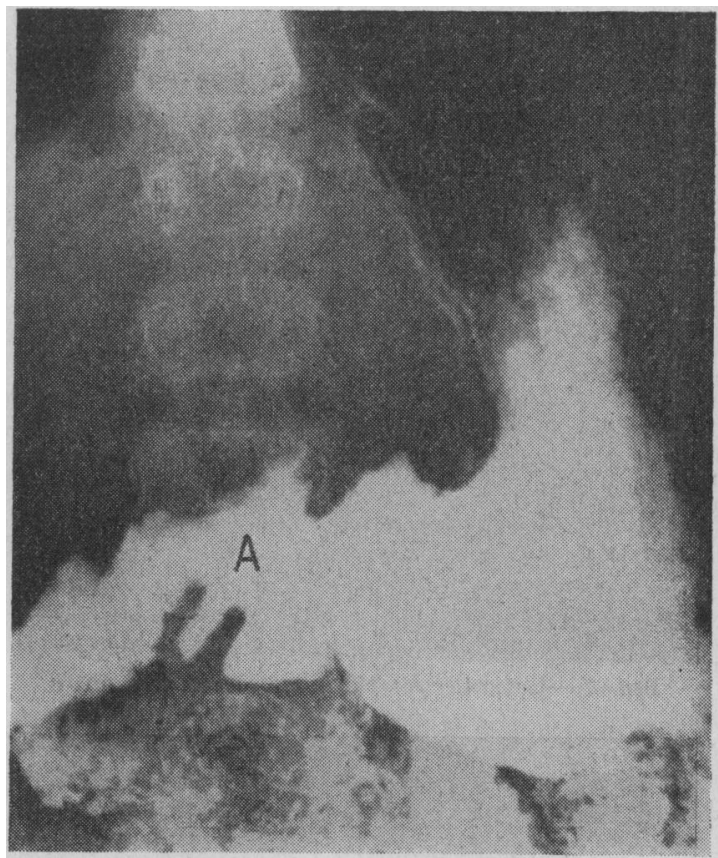

Fic. 5.-Case 3. $A=$ Pyloroplasty.

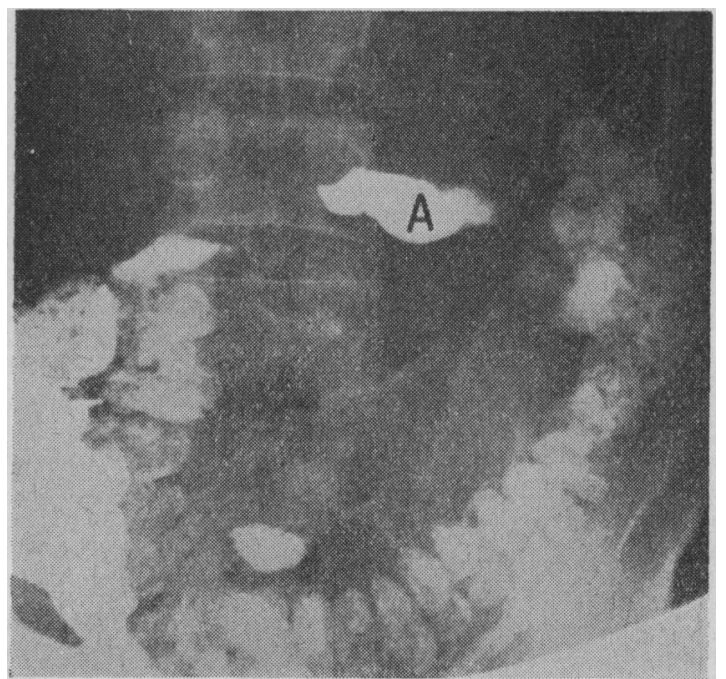

Fig. 6.-Case 3. $A=$ Ten-hour retention.
Fig. 3-Case 2. $A=$ Antral retention $B=$ Retention in cup-and-spill stomach. 
Case 4.-A man aged 56 (blood group A). Vagotomy and gastrojejunostomy was performed for what was thought to be chronic duodenal ulceration. In fact we now know that the peptic disease was exactly at the pyloric ring. After four years of good health the patient began to lose weight and to complain of loss of appetite. His háemoglobin had fallen to $55 \%$. A provisional diagnosis was made of gastric carcinoma. Barium-meal examination showed a very narrow yet smooth prepyloric segment between the pylorus and the gastrojejunostomy stoma (Fig. 7). At operation no neoplasm was found. A finger inserted through a small prepyloric gastrotomy incision revealed severe stenosis exactly at the pyloric ring, and the mucous membrane between the pylorus and the stoma was grossly haemorrhagic. This severe gastritis, limited to this segment, had caused continued occult bleeding. Completeness of nerve section at the first operation was confirmed at the second by the stimulation test. The gastrojejunostomy was taken down and a pyloroplasty

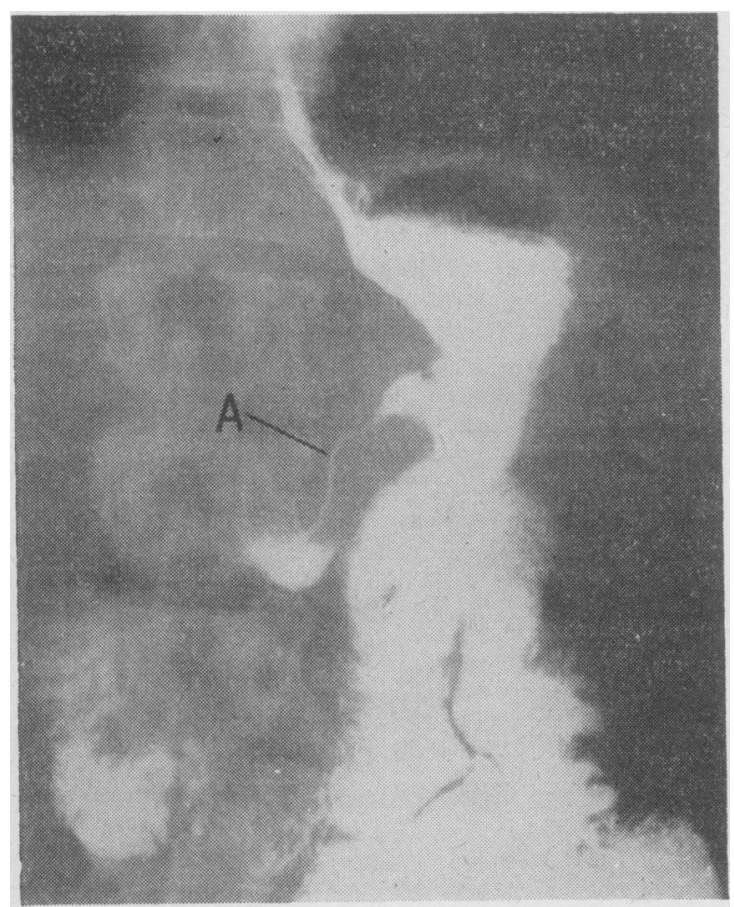

FIG. 7.-Case 4. $A=$ Narrow prepyloric segment.

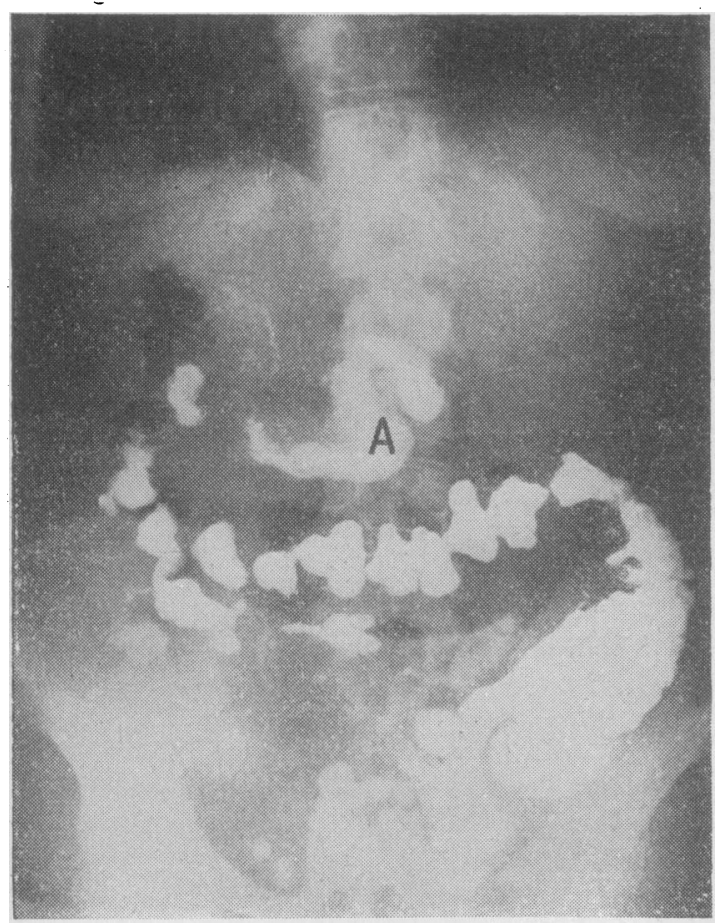

Fig. 8.-Case 5. $A=$ Antral retention. made. The patient has remained in good health and maintained his haemoglobin level since the operation.

Case 5.-A woman aged 71 (blood group $O$, non-secretor). Vagotomy and pyloroplasty was done for duodenal ulceration, and nerve section was proved complete by the electrical stimulation test. At operation duodenal narrowing was found. Six months later she was admitted to hospital with melaena but without symptoms of recurrent ulceration. After the haemorrhage had subsided, the insulin test appeared to show complete nerve section. Gastric retention was demonstrated on barium-meal examination. A small gastric residue was present in the 10-hour film (Fig. 8). $X$-ray examination using the television screen showed that there was persistent narrowing of the duodenum as it left the pyloroplasty stoma (Fig. 9). No ulcer crater could be demonstrated. It would seem that the bleeding in this case occurred, as in Case 4, from a gastritis in the retentioned antrum. The pyloroplasty incision had not been carried through and distal to the stenotic duodenum. Fortunately there has been no further trouble, and the patient remains well two years later.

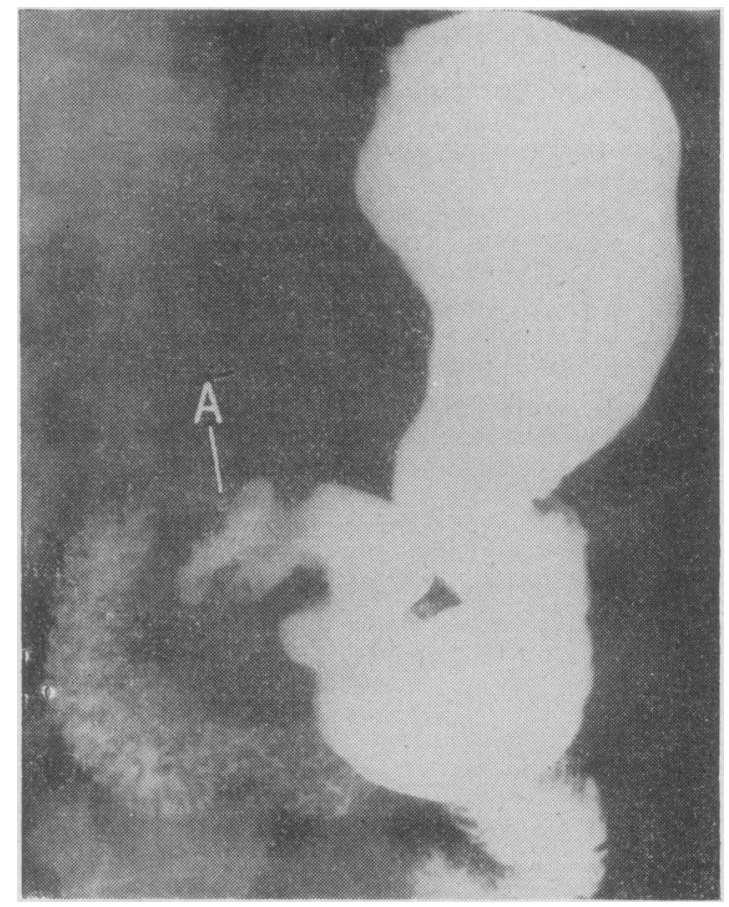

Fig. 9.-Case 5. $A=$ Narrow duodenum leaving pyloroplasty.

\section{Discussion}

Some surgeons, both in Britain and in America, advocate the so-called "combined operation" of vagotomy and antrectomy rather than vagotomy and simple drainage in the surgical treatment of some or all cases of chronic duodenal ulceration. In America the use of this operation in all cases has received the support of Harkins et al. (1960) in Seattle and of Smithwick et al. (1961). In Britain, Gillespie and Kay (1961) and Bruce et al. (1959) have held that vagotomy with simple drainage does not cure all cases of duodenal ulceration, and that the operation must be chosen for each patient, and that this choice depends on studies of gastric acid. These workers have argued that in some patients with duodenal ulceration there is antral dominance, and these need antrectomy (hemigastrectomy) as well as vagotomy. Kay attempted to select this group by means of his " medical vagotomy modification of the augmented histamine test."

More recently Kay (1964) has come to think that patients with blood group $\mathrm{O}$ who do not secrete the blood-group antigen into the saliva also need vagotomy and antrectomy, because they are more liable to recurrent ulceration after vagotomy.

Neither the antral-dominance theory nor the blood group and blood-group-antigen theory is supported by our work. 
Although Case 1 is of blood group $O$ and a non-secretor, he has remained perfectly well since his incomplete vagotomy was completed two years ago. Case 2 also is blood group $O$ and a non-secretor. He had antral retention and a gastrojejunal ulcer, but has been symptom-free for three years and no ulcer has been found on $x$-ray examination.

These two cases may suggest that duodenal ulceration is more likely to occur in patients of blood group $O$ who are nonsecretors, but they did not suggest that any thing more than complete vagotomy and good antral drainage is ever required to cure duodenal ulceration.

Cases 3 and 4 are both group $A$. Case 5 is group $O$ and a non-secretor. She has never had symptoms of recurrent ulceration, nor has there ever been $x$-ray evidence of it.

If, as we believe, recurrent ulceration after vagotomy and simple drainage occurs only in the presence of incomplete nerve section or an antrum badly drained by technical error, then the operation may be used in all cases and there is never need to estimate gastric acids or to consider the blood group and bloodgroup-antigen factor. It is true that acid studies may be helpful in the diagnosis of the Zollinger-Ellison syndrome, but if the pancreas is routinely palpated at operation, even here they are unnecessary.

Pyloroplasty, for several reasons, seems preferable to gastrojejunostomy. In the early post-operative period it is entirely free from loop obstructions and bilious vomiting, and later bilious regurgitation and dumping are rare. This is certainly not so after gastrojejunostomy.

If gastrojejunostomy is performed proximal to a stenosed pylorus or duodenum, antral retention may cause gastrojejunal ulceration. If pyloroplasty is used the incision should be long $(8 \mathrm{~cm}$.) and should divide completely any duodenal narrowing. It is closed preferably with a single layer of interrupted thread sutures ; then the stoma is large and antral emptying should be satisfactory.

\section{Summary}

In 200 patients in whom the electrical stimulation test has been used at the time of vagotomy and simple drainage for duodenal ulcer only one patient has come to further operation for recurrent ulceration. In this case incomplete nerve section was found. In another, gastrojejunal ulceration occurred after vagotomy and gastrojejunostomy, and was apparently due to antral retention. It healed spontaneously and has remained so. In two other patients gastric bleeding with anaemia had apparently been caused by a gastritis in an antrum retentioned by a badly-made drainage operation.

This interim report suggests that there is never need to excise the antrum if vagotomy and simple drainage is properly performed.

\section{REPERBNCES}

Austen, W. G., and Edwards, H. C. (1961). Gut, 2, 158.

Bancroft, F. W. (1932). Amer. F. Surg., 16, 223.

Bruce, J., Card, W. I., Marks, I. N., and Sircus, W. (1959). F. roy. Coll. Surg. Edinb., 4, 85

Burge, H. (1958). Eleventh Alexander Simpson Smith Memorial Lecture, West London Hospital Medical School, London.

and Clark, P. A. (1960). Gastroenterology, 39, 572

- and Vane, J. R. (1598). Brit. med. 7. 1, 615

Carman, R. D. (1917). Amer. f. Roentgenol., 4, 552.

Dragstedt, L. R (1948). Gastroenterology, 11, 468

Edwards, L. W., Classen, K. L., and Sawyers, J. L. (1960). Ann. Surg., 151, 827 .

Feggetter, G. Y. (1959). Proc. roy. Soc. Med., 52, 838

Gillespie, I. E., and Kay, A. W. (1961). Brit. med. f., 1, 1557

Harkins, H. N., Jesseph, J. E., Stevenson, J. K., and Nyhus, L. M. (1960). Arch. Surg., 80, 743.

Hoerr, S. O. (1959). Cleveland Clin. Quart., 26, 170.

Holt, R. L. (1959). Proc. roy. Soc. Med., 52, 837

Kay, A. W. (1964). Brit. med. ₹., 1, 754.

Rigler, S. P. (1959). In The Physiology and Treatment of Peptic Ulcer, edited by J. G. Allen, p. 176. Univ. of Chicago Press, Chicago.

Smithwick, R. H., Harrower, H. W., and Farmer, D. A. (1961). Amer. 7. Surg., 101, 325.

Stempien, S. J., Dagradi, A. E., and Seifer, H. W. (1959). World Congress of Gastroenterology, 2, 1026. Williams and Wilkins, Baltimore.

Weinberg, J. A., Stempien, S. J., Movius, H. J., and Dagradi, A. B. (1956). Amer. F. Surg., 92, 202.

\title{
Infections by Organisms of Psittacosis/Lymphogranuloma Venereum Group in the West of Scotland
}

\author{
N. R. GRIST,* M.B., B.SC., F.R.C.P.ED., M.C.PATH. ; C. MCLEAN, † F.I.M.L.T.
}

Brit. med. F., 1964, 2, 21-25

Psittacosis, ornithosis, lymphogranuloma venereum (L.G.V.), trachoma, and inclusion conjunctivitis are well-recognized human diseases caused by viruses of a group which is widespread in nature. These organisms parasitize warm-blooded animals and birds, sometimes causing acute pneumonic illness, enteritis of calves, abortion of ewes, or encephalomyelitis of cattle. Characteristically, they may cause in their usual hosts chronic or latent infections. Thus in man trachoma and L.G.V. are chronic infections with granulomatous and fibrotic reactions, while chronic symptomless infections of the female genital tract by venereal-transmitted virus provide the infectious reservoir of inclusion conjunctivitis. Chronic pulmonary infection of man with psittacosis virus has also been described (Meyer and Eddie, 1951).

The causal organisms of this group are obligatory parasites of specific cells and resemble viruses in the intimacy of integration with their host cells. Unlike typical viruses, they are susceptible to several antibiotics and sulphonamides, and are large enough to be seen through the optical microscope during most of their complex developmental cycle. These characteristic morphological appearances are utilized in the routine microscopical diagnosis of trachoma and inclusion blennorrhoea. A common thermostable polysaccharide antigen is shared by viruses of the psittacosis-L.G.V. group. Complement-fixing (C.F.) antibodies to this antigen appear during infection by psittacosis and L.G.V. viruses, and detection of these antibodies is the basis of routine serological diagnosis of such infections.

The following report describes human infections diagnosed by the use of this serological test in Glasgow from 1950 to 1963 inclusive, together with a limited survey of non-human reservoirs of infection in this area.

\footnotetext{
* Reader in Viral Epidemiology, University of Glasgow.

tChief Technician, Regional Virus Laboratory, Ruchill Hoopiral, Glasgow.
} 